\title{
Confidence Limits for the Abscissa of Intersection of Two Linear Regressions
}

\author{
James J. Filliben \\ Institute for Basic Standards, National Bureau of Standards, Washington, D.C. 20234 \\ and \\ John E. McKinney \\ Institute for Materials Research, National Bureau of Standards, Washington, D.C. 20234
}

(August 25, 1972)

\begin{abstract}
A method to determine the confidence limits for the abscissa of the intersection of two linear regressions has been developed. This method does not require the assumption of equal variance for the two regressions, as was necessary with previous methods. A numerical example is included on thermodynamic, glass transition data for which this method is applicable. Comparisons are made between the results using equal and unequal variance assumptions. A FORTRAN subroutine is included for computations using both assumptions.
\end{abstract}

Key words: Abscissa; confidence limits; glass transition; intercept; intersection; linear; regression; second order transition; statistics; variance.

\section{Introduction}

In this paper confidence limits are derived for the abscissa of the intersection point of two linear regressions. As illustrated in figure 1, it is assumed that there are independent realizations of two linear regressions at ordered values of a single independent variable $X$. The problem is to determine confidence limits for the abscissa $X_{0}$ of the intersection point of the two linear regressions.

This problem was originally considered and solved by Fisher $[1]^{1}$ and later by Kastenbaum [2], but under the assumption of a common error variance for the two regression lines. Hinkley [3] derived the asymptotic distribution of the maximum likelihood estimator for the intersection point abscissa of two linear regressions, also assuming equal variances. Robison [4] presented estimators and confidence limits for the intersection point abscissa of two polynomial regressions under the equal variance assumption. Hudson [5] derived least squares estimators (but no confidence limits) for the intersection point abscissas of two or more general regression models for the unequal variance case.

The principal contribution of the present paper is a derivation of confidence limits for the intersection point abscissa without resorting to the equal variance assumption. Although only the linear regression case is considered below, extension of results to more complicated regression models is possible.

The results of this derivation have direct application to thermodynamic data to evaluate the uncertainties in the second order transition temperature $T_{2}$ and the glass transition temperature $T_{g}$.

AMS Subject Classification: 62.55 .

${ }^{1}$ Figures in brackets indicate the literature references at the end of this paper. 


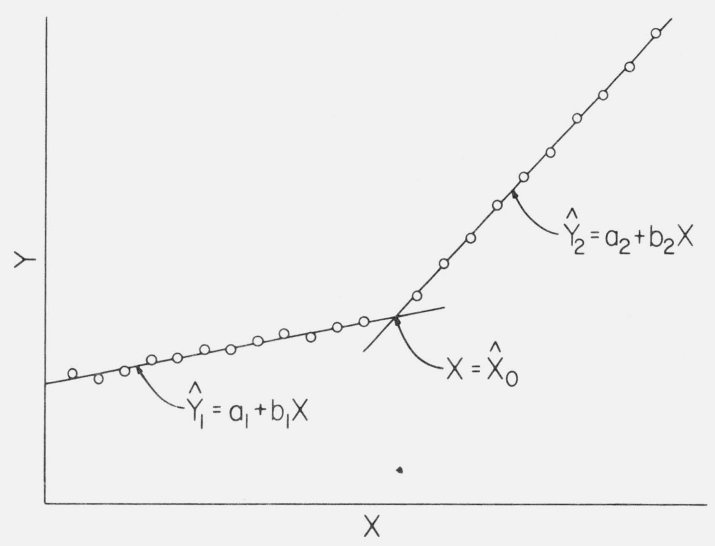

FIGURE 1. Intersection of two linear regressions.

The second order transition is an equilibrium phenomenon, whereas the glass transition is a nonequilibrium one for which $T_{g}$ depends upon the thermodynamic history by which the glass is formed. Both transitions may be manifested by discontinuities in the second order properties (for example, thermal expansivity or heat capacity) with respect to temperature. The corresponding first order properties (volume or enthalpy) vary with temperature in a manner similar to $Y$ versus $X$ in figure 1 for which the transition temperature may be determined by the intersection of the two straight lines representative of the response in the two regions. Accordingly, this method may be applied directly to any of the first order properties to determine the confidence bands of the transition temperature as defined ${ }^{2}$ from the intersection of the two regression lines. The method is sufficiently general that it is applicable to cases where data are not available in the proximity of the intersection, which, of course, leads to a less accurate prediction of its abscissa.

Two methods are described to evaluate the confidence limits for the abscissa of intersection. These are based on the assı:mptions of equal and unequal variances for the regression lines determined from the two sets. The advantage of the equal variance case is that the underlying assumption of equal variance permits a relatively simple development of the method, whereas the advantage of the unequal variance case is, of course, in its more general application. The ANSI FORTRAN subroutine to calculate the confidence limits for both cases is given in the appendix, and numerical examples are included in later discussions.

\section{Derivation of Confidence Limits}

As illustrated in figure 1 , let $\hat{Y}_{1}(X)=a_{1}+b_{1} X$ and $\hat{Y}_{2}(X)=a_{2}+b_{2} X$ be two fitted least squares regressions based on $n_{1}$ and $n_{2}$ observations $\left(X_{i j}, i=1,2 ; j=1,2, \ldots, n_{i}\right)$ respectively, where the random variables $\hat{Y}_{i}(X)$ are assumed to be normally and independently distributed about the true unknown regression lines $\mu_{i}(X)=\alpha_{i}+\beta_{i} X$ with variances $\sigma_{i}^{2}$. $\left(\alpha_{i}, \beta_{i}\right.$, and $\sigma_{i}^{2}$ are true, but unknown, parameter values.)

The problem is to determine confidence limits for the abscissa $X_{0}$ of the intersection point $\left(X_{0}, Y_{0}\right)$ of the two unknown regression lines.

The starting point for our derivation is the fact that $a_{i}$ and $b_{i}$, the usual least squares estimators, are linear combinations of normally distributed variables and hence themselves are normally distributed. Thus for all $X, \hat{Y}_{i}(X)=a_{i}+b_{i} X$ is also normally distributed, as is the difference $\hat{Y}_{1}(X)-\hat{Y}_{2}(X)$. Since $\hat{Y}_{1}(X)-\hat{Y}_{2}(X)$ has mean $\mu_{1}(X)-\mu_{2}(X)$ and variance

${ }^{2}$ This definition of the glass temperature is one of several which are not necessarily equivalent. 
$\sigma_{1}^{2} V_{1}(X)+\sigma_{2}^{2} V_{2}(X)$, where

$$
\begin{aligned}
V_{i}(X) & =\frac{1}{n_{i}}+\frac{\left(X-\bar{X}_{i}\right)^{2}}{S_{i}^{2}}, \quad i=1,2 \\
\bar{X}_{i} & =\frac{1}{n_{i}} \sum_{j=1}^{n_{i}} X_{i j}, \quad i=1,2 \\
S_{i}^{2} & =\sum_{j=1}^{n_{i}}\left(X_{i j}-\bar{X}_{i}\right)^{2}, \quad i=1,2,
\end{aligned}
$$

then it follows that all $X$

$$
\frac{\left[\hat{Y}_{1}(X)-\hat{Y}_{2}(X)\right]-\left[\mu_{1}(X)-\mu_{2}(X)\right]}{\sqrt{\sigma_{1}^{2} V_{1}(X)+\sigma_{2}^{2} V_{2}(X)}}
$$

has a standardized (mean 0 , variance 1 ) normal distribution.

Consider first of all the equal variance case $\left(\sigma_{1}^{2}=\sigma_{2}^{2}=\sigma^{2}\right.$, say), treated earlier [1]. It is seen that eq (2) simplifies to

$$
\frac{\left[\hat{Y}_{1}(X)-\hat{Y}_{2}(X)\right]-\left[\mu_{1}(X)-\mu_{2}(X)\right]}{\sigma \sqrt{V_{1}(X)+V_{2}(X)}} .
$$

Thus

$$
\frac{\left[\hat{Y}_{1}(X)-\hat{Y}_{2}(X)\right]-\left[\mu_{1}(X)-\mu_{2}(X)\right]}{s \sqrt{V_{1}(X)+V_{2}(X)}}
$$

has a $t$ distribution with $n_{1}+n_{2}-4$ degrees of freedom, where $s$ is the square root of the pooled unbiased estimator of $\sigma^{2}$ :

$$
s=\sqrt{\frac{\left(n_{1}-2\right) s_{1}^{2}+\left(n_{2}-2\right) s_{2}^{2}}{n_{1}+n_{2}-4}},
$$

and where $s_{i}^{2}$ is the unbiased estimator for $\sigma_{i}^{2}$ given by the residual variance obtained from the least squares fit of line $i$.

The quantity (4) is distributed as $t$ for all $X$, and in particular for $X=X_{0}$ in which case $\mu_{1}(X)-\mu_{2}(X)$ vanishes. It then follows that for every probability $p(0<p<1)$

$$
\operatorname{Prob}\left\{\left(\frac{\hat{Y}_{1}\left(X_{0}\right)-\hat{Y}_{2}\left(X_{0}\right)}{s \sqrt{V_{1}\left(X_{0}\right)+V_{2}\left(X_{0}\right)}}\right)^{2} \leqslant\left(G_{t}\left(\frac{1+p}{2}\right)\right)^{2}\right\}=p
$$

where $G_{t}\left(\frac{1+p}{2}\right)$ is the $100\left(\frac{1+p}{2}\right)$ percent point of the $t$ distribution with $n_{1}+n_{2}-4$ degrees of freedom. The squared numerator $\left[\hat{Y}_{1}\left(X_{0}\right)-\hat{Y}_{2}\left(X_{0}\right)\right]^{2}$ and squared denominator $s^{2}\left[V_{1}\left(X_{0}\right)\right.$ $\left.+V_{2}\left(X_{0}\right)\right]$ above are both quadratics in $X_{0}$. Thus eq (6) is of the form

$\operatorname{Prob}\left\{\frac{Q_{1}}{Q_{2}} \leqslant G^{2}\right\}$ (or equivalently Prob $\left\{Q_{1}-G^{2} Q_{2} \leqslant 0\right\}$ ) where $Q_{i}$ denote quadratic expressions, and $G$ denotes $G_{t}\left(\frac{1+p}{2}\right)$. Since $Q_{1}-G^{2} Q_{2}$ is itself a quadratic (say $A X_{0}^{2}+B X_{0}+C$ ), then the 
desired confidence interval consists of those $X_{0}$ such that $A X_{0}^{2}+B X_{0}+C \leqslant 0$ and the desired confidence limits for $X_{0}$ are simply the two roots of $A X_{0}^{2}+B X_{0}+C=0$.

The coefficients $A, B$, and $C$ are rather tediously derived; omitting the intermediate algebra, these coefficients are

$$
\begin{aligned}
& A=\left(b_{1}-b_{2}\right)^{2}-s^{2} G^{2}\left[\frac{1}{S_{1}^{2}}+\frac{1}{S_{2}^{2}}\right] \\
& B=2\left(a_{1}-a_{2}\right)\left(b_{1}-b_{2}\right)+2 s^{2} G^{2}\left[\frac{\bar{X}_{1}}{S_{1}^{2}}+\frac{\bar{X}_{2}}{S_{2}^{2}}\right] \\
& C=\left(a_{1}-a_{2}\right)^{2}-s^{2} G^{2}\left[\frac{1}{n_{1}}+\frac{1}{n_{2}}+\frac{\bar{X}_{1}^{2}}{S_{1}^{2}}+\frac{\bar{X}_{2}^{2}}{S_{2}^{2}}\right] .
\end{aligned}
$$

It is of interest to note that the midpoint $-B / 2 A$ of the confidence interval is not identical to the maximum likelihood estimator

$$
\hat{X}_{0}=-\frac{a_{1}-a_{2}}{b_{1}-b_{2}}
$$

however, the two estimators converge to a common limit as $s^{2} \rightarrow 0$. For a less detailed derivation of the above confidence interval results, see references [1-3].

For the more general $\sigma_{1}^{2} \neq \sigma_{2}^{2}$ case, the distributional complications which arise are identical to those encountered in the Behrens-Fisher 2-means problem [6]. The solution outlined below is an extension of the Welch-Aspin [7, 8,9] solution to the Behrens-Fisher problem. Proceeding in a manner analogous to Welch and Aspin, we see that for all $X$,

$$
\frac{\left[\hat{Y}_{1}(X)-\hat{Y}_{2}(X)\right]-\left[\mu_{1}(X)-\mu_{2}(X)\right]}{\sqrt{s_{1}^{2} V_{1}(X)+s_{2}^{2} V_{2}(X)}}
$$

has approximately a $t$ distribution with $\nu$ degrees of freedom, where $\nu$ is given by

$$
\frac{1}{\nu}=\frac{1}{n_{1}-2}\left(\frac{V_{1}\left(X_{0}\right)}{V_{1}\left(X_{0}\right)+V_{2}\left(X_{0}\right)}\right)^{2}+\frac{1}{n_{2}-2}\left(\frac{V_{2}\left(X_{0}\right)}{V_{1}\left(X_{0}\right)+V_{2}\left(X_{0}\right)}\right)^{2}
$$

A minor complication at this point is the fact this $X_{0}$ in (10) is an unknown parameter. In order to arrive at an approximate value for $\nu$ the maximum likelihood estimate $\hat{X}_{0}$ (as defined in (8)) is used. The development now parallels the $\sigma_{1}^{2}=\sigma_{2}^{2}$ case, and so again $100 p$ confidence limits for $X_{0}$ are obtained by solving a quadratic equation, but with the following slightly-modified coefficients:

$$
\begin{aligned}
& A=\left(b_{1}-b_{2}\right)^{2}-G^{2}\left[\frac{s_{1}^{2}}{S_{1}^{2}}+\frac{s_{2}^{2}}{S_{2}^{2}}\right] \\
& B=2\left(a_{1}-a_{2}\right)\left(b_{1}-b_{2}\right)+2 G^{2}\left[\frac{s_{1}^{2} \bar{X}_{1}+s_{2}^{2} \bar{X}_{2}}{S_{1}^{2}}+\frac{s_{2}^{2}}{S^{2}}\right] \\
& C=\left(a_{1}-a_{2}\right)^{2}-G^{2}\left[\frac{s_{1}^{2}}{n_{1}}+\frac{s_{2}^{2}}{n_{2}}+\frac{s_{1}^{2} \bar{X}_{1}^{2}}{S_{1}^{2}}+\frac{s_{2}^{2} \bar{X}_{2}^{2}}{S_{2}^{2}}\right]
\end{aligned}
$$


Note that although the unequal variance case basically parallels the equal variance case, the former does not numerically reduce to the latter when $s_{1}^{2}=s_{2}^{2}$. The confidence intervals usually are distinct even when $s_{1}^{2}=s_{2}^{2}$. In deciding whether to use the equal variance results or the unequal variance results, there are two considerations to be taken into account: physical theory and the variance ratio $F$ test. The general rule of thumb is to always use the unequal variance results unless the following two conditions are simultaneously satisfied: (1) there is a firm physical reason for assuming equal variances; and (2) the $F$ ratio $S_{1}^{2} / S_{2}^{2}$ is not significantly different from unity. This recommended procedure is at times conservative, but more important, it is less assumptiondependent and hence more generally valid.

In the appendix, an ANSI FORTRAN subroutine is presented which first of all tests to see whether the equal variance assumption is tenable, and secondly computes confidence limits for $X_{0}$ for both the equal variance and the unequal variance cases. The subroutine is double precision in input, internal operation, and output. Definitions of input parameters and instructions for the use of the subroutine are given in the comment statements within the subroutine.

\section{Example: Calculation of the 95 percent Confidence Limits for the Pressure-Dependent Glass Temperature}

As an example, the 95 percent confidence limits have been calculated for the pressuredependent glass transition temperature of poly(vinyl acetate), an amorphous, glass-forming polymer. The PVT (pressure-volume-temperature) data for the glass, designated as set 1 , are given in table 1, and the data for the liquid, designated as set 2, are given in table 2. Both sets of data,

TABLE 1. Specific volume values for the glassy region

\begin{tabular}{r|c|c|c|r|r|r|r|r|r}
\hline \hline$T / P$ & 0 & 100 & 200 & 300 & 400 & 500 & \multicolumn{1}{c}{600} & 700 & 800 \\
\hline-30 & 0.82884 & 0.82654 & 0.82438 & 0.82225 & 0.82017 & 0.81816 & 0.81613 & 0.81419 & 0.81237 \\
-25 & .83002 & .82768 & .82547 & .82334 & .82121 & .81914 & .81715 & .81516 \\
-20 & .83110 & .82874 & .82648 & .82430 & .82218 & .82010 & .81808 & .81606 \\
-15 & .83238 & .82997 & .82767 & .82549 & .82331 & .82117 & .81919 & .81717 \\
-10 & .83350 & .83117 & .82886 & .82663 & .82443 & .82224 & .82022 & .81817 \\
-5 & .83467 & .83233 & .83003 & .82774 & .82557 & .82340 & .82131 & .81933 \\
0 & .83581 & .83351 & .83115 & .82889 & .82666 & .82447 & .82237 & .82033 \\
5 & .83706 & .83478 & .83241 & .83012 & .82794 & .82569 & .82355 & .82140 \\
10 & .83812 & .83593 & .83359 & .83130 & .82903 & .82679 & .82465 & .82248 \\
15 & .83937 & & & & & & & .81941 \\
20 & .84061 & & & & & & & \\
\hline
\end{tabular}

Units: $T$ in ${ }^{\circ} \mathrm{C}, P$ in $\mathrm{B}$ ars, $v$ in $\mathrm{cm}^{3} / \mathrm{g}$.

TABLE 2. Specific volume data for the liquid region

\begin{tabular}{r|c|r|r|r|r|r|r|r|r}
\hline \hline$T / P$ & 0 & 100 & 200 & 300 & 400 & 500 & 600 & 700 & 800 \\
\hline 35 & 0.84572 & 0.84148 & & & & & & \\
40 & .84870 & .84444 & 0.84041 & 0.83670 & & & \\
45 & .85174 & .84733 & .84321 & .83921 & 0.83549 & 0.83184 & & \\
50 & .85486 & .85041 & .84608 & .84206 & .83817 & .83447 & 0.83087 & 0.82757 & \\
55 & .85791 & .85349 & .84894 & .84491 & .84092 & .83709 & .83340 & .82988 & 0.82666 \\
60 & .86104 & .85628 & .85179 & .84769 & .84367 & .83980 & .83607 & .83256 & .82904 \\
65 & .86407 & .85933 & .85472 & .85052 & .84648 & .84250 & .83874 & .83523 & .83174 \\
70 & .86723 & .86218 & .85755 & .85324 & .84913 & .84507 & .84108 & .83734 & .83378 \\
75 & .87038 & .86536 & .86038 & .85594 & .85171 & .84762 & .84367 & .84000 & .83626 \\
80 & .87343 & .86829 & .86342 & .85881 & .85453 & .85036 & .84641 & .84257 & .83889 \\
85 & .87669 & .87140 & .86636 & .86169 & .85728 & .85308 & .84911 & .84532 & .84155 \\
90 & .87986 & .87438 & .86923 & .86444 & .86000 & .85574 & .85172 & .84776 & .84396 \\
95 & .88301 & .87741 & .87207 & .86722 & .86269 & .85823 & .85424 & .85025 & .84641 \\
100 & .88622 & .88043 & .87500 & .87012 & .86534 & .86095 & .85678 & .85284 & .84904 \\
\hline
\end{tabular}

Units: $T$ in ${ }^{\circ} \mathrm{C}, P$ in bars, $v$ in $\mathrm{cm}^{3} / \mathrm{g}$ 
taken from reference [10], are illustrated in figure 2, where the specific volume $v$ taken from the above tables is plotted as a function of temperature at the different pressures indicated. The specific volume data $v_{1}(T, P)$ for the glass (at temperatures between -30 and $20^{\circ} \mathrm{C}$ ) were obtained after the glass was formed at atmospheric pressure at a constant cooling rate of $5{ }^{\circ} \mathrm{C} / \mathrm{h}$ commencing at equilibrium in the liquid region. The data $v_{2}(T, P)$ for the liquid $\left(35\right.$ to $100{ }^{\circ} \mathrm{C}$ ) are taken to be in true equilibrium. A characteristic of a glass is its large increase in its viscoelastic relaxation times with decreasing temperature. The glass transition is a manifestation of the increase of relaxation times during formation of the glass. Although the data shown here for the glass are not representative of the attainment of true equilibrium, the relaxation times at these temperatures are very long in comparison to experimental times. Accordingly, the glass data may be treated as being in apparent equilibrium (pseudoequilibrium) over any practical time scale, as has been done in this case.

Since the volume isobars vary nearly linearly with temperature in both the liquid and glass regions, and since the slopes for each isobar in these regions are distinct, the results of section 2 are applicable. By treating each of the two regions separately, each of the volume isobars may be represented by two distinct regression lines of the form

$$
\hat{v}_{i}=a_{i}+b_{i} T, \quad i=1,2 .
$$

The intersection of these two regression lines at each pressure gives the "maximum likelihood estimator"

$$
\hat{T}_{g}=-\frac{a_{1}-a_{2}}{b_{1}-b_{2}}
$$

which is taken here as an estimate of the true, but unknown, glass temperature $T_{g}$ for the particular thermodynamic history by which the glass was formed. In figure 2 the regression lines of the form of eq (12) are shown by the solid lines with positive slope at each pressure. The solid line

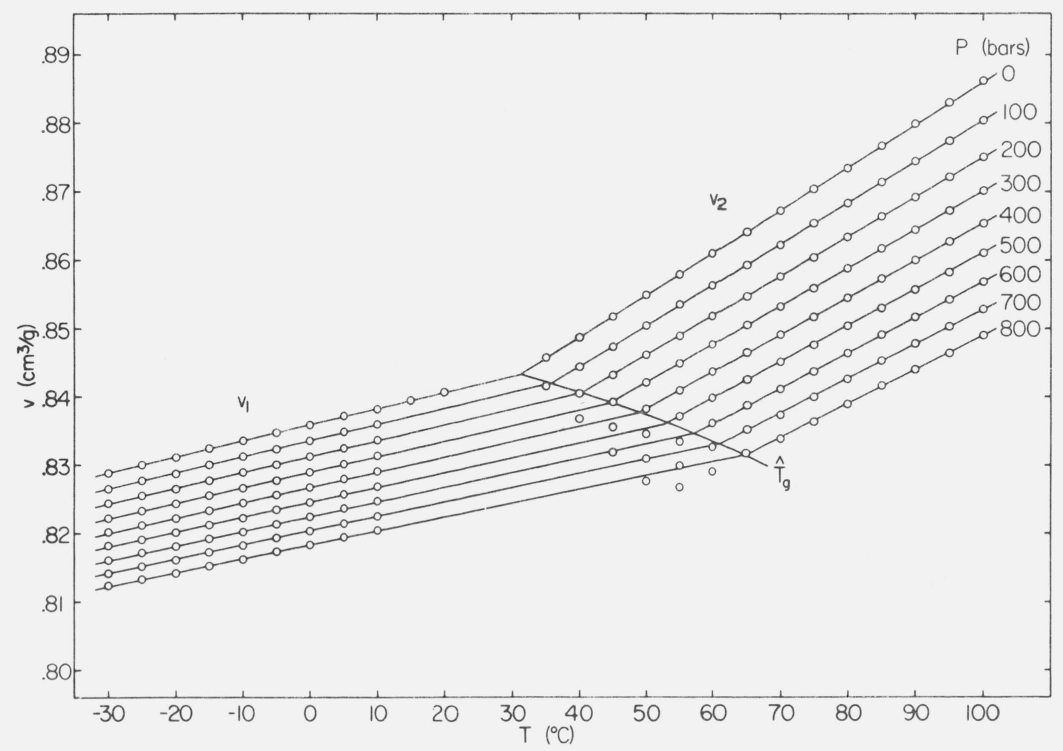

FIGURE 2. Specific volume of poly(vinyl acetate) as a function of temperature at different pressures.

An estimate of the glass transition is obtained from the intersection of the volume isobars taken to be linear with temperature. 
with negative slope gives the positions of $\hat{T}_{g}$, which depend strongly on the pressure. It is seen that some of the data representative of the liquid region fall to the left of $\hat{T}_{g}$. Although this result may be paradoxical, it is simply a consequence of the fact that the liquid data are equilibrium data, and the glass are pseudoequilibrium data ${ }^{4}$ resulting from the particular thermodynamic history by which the glass was formed.

Ninety-five percent confidence limits for $T_{g}$ were calculated using both the equal and unequal variance assumptions. The paired statistical quantities necessary to calculate the confidence limits are given in tables 3 and 4 for the glass and liquid, respectively, where $P$ is the pressure, $a_{i}$ is the intercept, $b_{i}$ is the slope, $s_{i}$ is the stanciard deviation of the residuals about the regression lines,

TABLE 3. Statistical data for the Glassy Region

\begin{tabular}{r|r|r|r|r|r|r}
\hline \hline$P$ & $a_{1}$ & $b_{1} \times 10^{3}$ & $s_{1} \times 10^{4}$ & \multicolumn{1}{|c|}{$n_{1}$} & $\bar{T}_{1}$ & $S_{1}^{2}$ \\
\hline 0 & 0.835843 & 0.23469 & 0.495 & 11 & -5.0 & 2750.0 \\
100 & .833531 & .23590 & .565 & 9 & -10.0 & 1500.0 \\
200 & .831192 & .23123 & .778 & 9 & -10.0 & 1500.0 \\
300 & .828928 & .22660 & .855 & 9 & -10.0 & 1500.0 \\
400 & .826716 & .22270 & .910 & 9 & -10.0 & 1500.0 \\
500 & .824512 & .21713 & 1.021 & 9 & -10.0 & 1500.0 \\
600 & .822417 & .21327 & .793 & 9 & -10.0 & 1500.0 \\
700 & .820328 & .20860 & .737 & 9 & -10.0 & 1500.0 \\
800 & .818301 & .20270 & .897 & 9 & -10.0 & 1500.0 \\
\hline
\end{tabular}

TABLE 4. Statistical data for the Liquid Region

\begin{tabular}{r|r|r|r|r|r|r}
\hline \hline$P$ & $a_{2}$ & $b_{2} \times 10^{3}$ & $s_{2} \times 10^{4}$ & $n_{2}$ & $\bar{T}_{2}$ & $S_{2}^{2}$ \\
\hline 0 & 0.823686 & 0.62355 & 1.146 & 14 & 67.5 & 5687.5 \\
100 & .820417 & .59934 & .869 & 14 & 67.5 & 5687.5 \\
200 & .817195 & .57760 & .683 & 13 & 70.0 & 4550.0 \\
300 & .814189 & .55834 & .832 & 13 & 70.0 & 4550.0 \\
400 & .811039 & .54362 & .565 & 12 & 72.5 & 3575.0 \\
500 & .808010 & .52946 & .589 & 12 & 72.5 & 3575.0 \\
600 & .804836 & .51987 & .952 & 11 & 75.0 & 2750.0 \\
700 & .802096 & .50698 & 1.341 & 11 & 75.0 & 2750.0 \\
800 & .799213 & .49703 & 1.564 & 10 & 77.5 & 2062.5 \\
\hline
\end{tabular}

$n_{i}$ is the number of observations, $\bar{T}_{i}$ is the average temperature, and $S_{i}^{2}$ is the sum of the sqlared temperature deviations:

$$
S_{i}^{2}=\sum_{j=1}^{n_{i}}\left(T_{i j}-\bar{T}_{i}\right)^{2}, \quad i=1,2
$$

The results of these calculations are summarized in table 5 for both the equal and unequal variance cases. $G$ is the 97.5 percent point of the $t_{\nu}$ distribution with $\nu$ degrees of freedom where $\nu=n_{1}+n_{2}^{\prime}-4$ in the equal variance case, and where $\nu$ is defined by eq (10) in the unequal variance case. $-A / 2 B$ is the midpoint of the confidence interval where $A$ and $B$ are defined by eqs (7) in the equal variance case and eqs (11) in the unequal variance case. $\Delta T$ is the 95 percent confidence interval width which is equal to the difference of the two roots of the quadratic equation for which the constants are defined in eqs (7) and (11) for equal variance and unequal variance, respectively. $s_{1} / s_{2}$ is the ratio of residual standard deviations, and $R$ is the ratio of $\Delta T$ for the equal variance case to $\Delta T$ for the unequal variance case. Perusal of table 5 reveals several interesting points. First, it is noted that the corresponding midpoints $-B / 2 A$ are essentially identical for the equal

${ }^{4}$ In principle, at least at temperatures over a limited range below $T_{g}$ shown here, the specific volume values for the glass will relax to extrapolations of the liquid isobars shown provided sufficient time is allowed. Since this time may be as long as several million years (depending on the temperature and pressure), the attainment of true equilibrium in all cases (as with the liquid values shown) is not practical. 
TABLE 5. Estimated values of $\mathrm{T}_{\mathrm{g}}$ and 95 percent Confidence Intervals

\begin{tabular}{|c|c|c|c|c|c|c|c|c|c|c|c|}
\hline \multirow{2}{*}{$P$} & \multirow{2}{*}{$\hat{T}_{g}$} & \multicolumn{4}{|c|}{ Equal variance } & \multicolumn{4}{|c|}{ Unequal variance } & \multirow{2}{*}{$\frac{s_{1}}{s_{2}}$} & \multirow{2}{*}{$R$} \\
\hline & & $\nu$ & $G$ & $-B / 2 A$ & $\Delta T$ & $\nu$ & $G$ & $-B / 2 A$ & $\Delta T$ & & \\
\hline 0 & 31.26 & 21 & 2.08 & 31.27 & 0.92 & 17 & 2.11 & 31.26 & 0.79 & 0.432 & 1.162 \\
\hline 1.00 & 36.08 & 19 & 2.09 & 36.09 & 1.18 & 9 & 2.26 & 36.09 & 1.02 & 0.650 & 1.158 \\
\hline 200 & 40.41 & 18 & 2.10 & 40.42 & 1.26 & 9 & 2.26 & 40.42 & 1.44 & 1.138 & 0.874 \\
\hline 300 & 44.43 & 18 & 2.10 & 44.44 & 1.62 & 8 & 2.31 & 44.44 & 1.80 & 1.028 & 0.898 \\
\hline 400 & 48.85 & 17 & 2.11 & 48.86 & 1.56 & 8 & 2.31 & 48.87 & 2.07 & 1.609 & 0.752 \\
\hline 500 & 52.84 & 17 & 2.11 & 52.85 & 1.84 & 8 & 2.31 & 52.86 & 2.53 & 1.734 & 0.729 \\
\hline 600 & 57.34 & 16 & 2.12 & 57.36 & 2.24 & 8 & 2.31 & 57.35 & 2.21 & .833 & 1.014 \\
\hline 700 & 61.10 & 16 & 2.12 & 61.13 & 3.03 & 7 & 2.36 & 61.11 & 2.34 & .549 & 1.296 \\
\hline 800 & 64.85 & 15 & 2.13 & 64.89 & 3.77 & 7 & 2.36 & 64.87 & 3.02 & .573 & 1.248 \\
\hline
\end{tabular}

and unequal variance cases, and these, in turn, are essentially identical to the maximum likelihood estimator $\hat{T}_{g}$. As mentioned earlier these quantities converge to the common limit $\hat{T}_{g}$ as $s_{i}^{2} \rightarrow 0$. Secondly, the confidence limits vary considerably between the equal and unequal variance cases (the ratio $R$ being at times both greater than or less than unity). In the case where $s_{1}$ and $s_{2}$ are nearly equal ( $P=300$ bars), $R$ differs considerably from unity; and in the case where $R$ is nearly unity $(P=700$ bars $), s_{1}$ and $s_{2}$ are considerably distinct. This behavior illustrates the fact that the equal variance case is not a special case of the unequal variance case as might be expected. Thirdly, there appears to be little correlation between the ratio of confidence interval widths and the ratio of resiciual standard deviations.

The values of the maximum likelihood estimator $\hat{T}_{g}$ and those for the 95 percent confidence interval width $\Delta T$ (each centered about its midpoint $-B / 2 A)$ for both the equal variance $\left(\sigma_{1}^{2}=\sigma_{2}^{2}\right)$ and the unequal variance $\left(\sigma_{1}^{2} \neq \sigma_{2}^{2}\right)$ cases are shown on figure 3 as functions of pressure. The median solid line is a quadratic regression of $\hat{T}_{g}$ with respect to pressure. The two extreme solid lines are quadratic regressions of the confidence limits with respect to pressure for the unequal variance case only. It is clear that a trend exists between the confidence interval and pressure. The principal reason for the divergence of the confidence interval with increasing pressure is that the difference $\left(\hat{T}_{g}-\bar{T}_{1}\right)$ between the estimated glass temperature $\hat{T}_{g}$ and the average temperature for the glass $\bar{T}_{1}$ also increases considerably with pressure as seen from figure 2 . Thus is apparent the importance of obtaining data in the vicinity of the glass temperature (or, in general, the intersection) in order to obtain an accurate estimate.

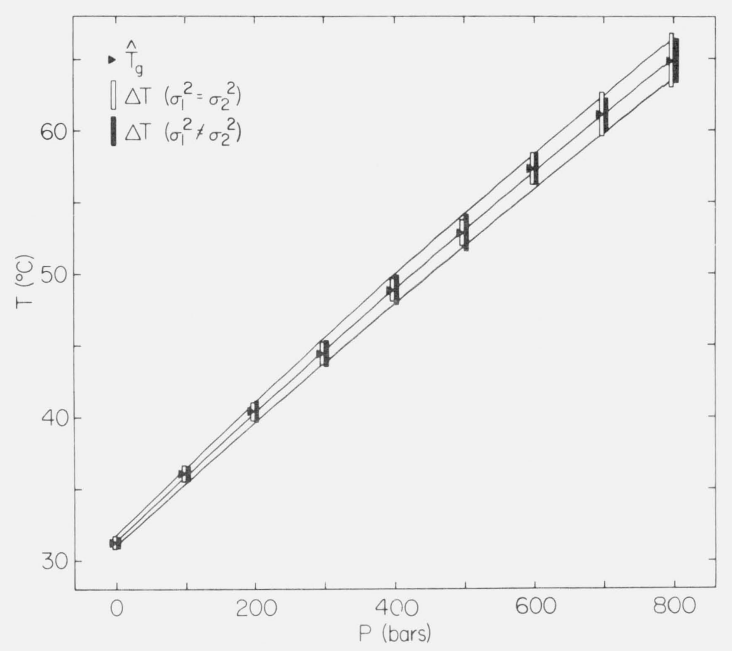

FIGURE 3. Maximum Likelihood Estimator, $\hat{\mathrm{T}}_{\mathrm{g}}$, and 95 percent Confidence Intervals as functions of pressure.

The solid lines are quadratic regressions of these quantities. 


\section{Appendix}

SUBROUTINE ABSCIS ( AN1 , AN2 , XBAR1 , XBAR2 , SSQDX1 , SSQDX2 , ALP1 , ALP2 , BET1

1, BET2 , RSD1 , RSD2 )

THE PURPOSE OF THIS ROUTINE IS TO COMPUTE 95 PERCENT CONFIDENCE LIMITS

FOR THE ABSCISSA OF THE INTERSECTION POINT OF TWO LINEAR REGRESSIONS

FOR BOTH THE EQUAL VARIANCES CASE AND THE UNEQUAL VARIANCES CASE

ANI = THE NUMBER OF $(\mathrm{X}, \mathrm{Y})$ PAIRS FOR LINE 1

AN2 $=$ THE NUMBER OF $(X, Y)$ PAIRS FOR LINE 2

XBARI = THE SAMPLE MEAN OF THE X VALUES FOR LINE 1

XBAR2 = THE SAMPLE MEAN OF THE X VALUES FOR LINE 2

SSQDXI = THE SUM OF THE SQUARED DEVIATIONS OF THE X VALUES FOR LINE 1 ABOUT XBARI

SSQDX2 = THE SUM OF THE SQUARED DEVIATIONS OF THE X VALUES FOR LINE 2 ABOUT XBAR2

ALPI = THE Y INTERCEPT OF LINE 1

ALP2 = THE Y INTERCEPT OF LINE 2

BETl = THE SLOPE OF LINE 1

BET2 = THE SLOPE OF LINE 2

RSDI = THE RESIDUAL STANDARD DEVIATION OF LINE 1

RSD2 = THE RESIDUAL STANDARD DEVIATION OF LINE 2

THIS ROUTINE IS DOUBLE PRECISION IN INPUT, INTERNAL OPERATION, AND OUTPUT DIMENSION Z $(30)$

DOUBLE PRECISION AN1, AN2, XBAR1, XBAR2, SSQDX1, SSQDX2

DOUBLE PRECISION ALP1, ALP2, BET1,BET2, RSD1, RSD2

DOUBLE PRECISION Z

DOUBLE PRECISION P,S, DELALP,DELBET, AML

DOUBLE PRECISION ANUEQ, ANUNEQ, GEQ, GNEQ, PP, HPP

DOUBLE PRECISION RATIO, AM, AN, HOLD

DOUBLE PRECISON A1, A2, A3, A, B1, B2, B3, B, C1 , C2 , C3, C

DOUBLE PRECISION DISC, ROOT1, ROOT2, AMID, WIDTH1, WIDTH2, RATWID

DOUBLE PRECISION DSQRT

DATA Z(1),Z(2),Z(3),Z(4),Z(5),Z(6),Z(7),Z(8),Z(9),Z(10),Z(11),

$1 \mathrm{Z}(12), \mathrm{Z}(13), \mathrm{Z}(14), \mathrm{Z}(15), \mathrm{Z}(16), \mathrm{Z}(17), \mathrm{Z}(18), \mathrm{Z}(19), \mathrm{Z}(20), \mathrm{Z}(21)$,

$\mathrm{IZ}(22), \mathrm{Z}(23), \mathrm{Z}(24), \mathrm{Z}(25), \mathrm{Z}(26), \mathrm{Z}(27), \mathrm{Z}(28), \mathrm{Z}(29), \mathrm{Z}(30) / 12.7026 \mathrm{D} 0$,

14.3027DO, 3.1824D0, 2.7764DO, 2.5706DO, 12.4469D0, 2.3646DO , 2.3060DO,

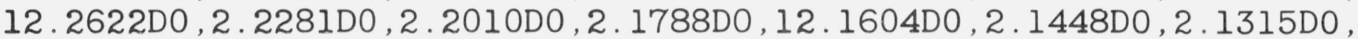

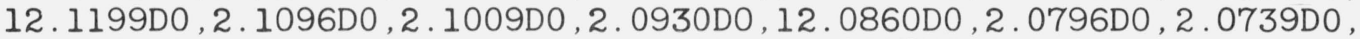

$12.0687 \mathrm{DO}, 2.0639 \mathrm{D} 0,2.0595 \mathrm{D} 0,2.0555 \mathrm{DO}, 12.0518 \mathrm{D} 0,2.0484 \mathrm{D} 0,2.0452 \mathrm{D} 0$,

$12.0423 \mathrm{DO} /$

COMPUTE NEEDED CONSTANTS

$\mathrm{P}=.95 \mathrm{D} 0$

$\mathrm{S}=\mathrm{DSQRT}\left(((\mathrm{ANl}-2.0 \mathrm{DD}))^{*} \mathrm{RSD} 1{ }^{*} \mathrm{RSD} 1+(\mathrm{AN} 2-2.0 \mathrm{ODO}){ }^{*} \mathrm{RSD} 2 *{ }^{*} \mathrm{RSD} 2\right) /(\mathrm{AN} 1+\mathrm{AN} 2-4.0$

IDO ))

DELALP=ALP1-ALP2

DELBET $=$ BET $1-B E T 2$

COMPUTE THE MAXIMUM LIKELIHOOD ESTIMATOR

$A M L=-D E L A L P / D E L B E T$

COMPUTE THE APPROPRIATE DEGREES OF FREEDOM FOR THE T PERCENT POINTS FOR THE EQUAL VARIANCES CASE AND FOR THE UNEQUAL VARIANCES CASE

$\mathrm{ANUEQ}=\mathrm{AN} 1+\mathrm{AN} 2-4.0 \mathrm{DO}$

$\mathrm{VI}=(1.0 D 0 / \mathrm{ANI})+(\mathrm{AML}-\mathrm{XBARI}) *(\mathrm{AML}-\mathrm{XBARI}) / \mathrm{SSQDX} I$

$\mathrm{V} 2=(1.0 \mathrm{D} 0 / \mathrm{AN2})+($ AML $-\mathrm{XBAR2}) *(\mathrm{AML}-\mathrm{XBAR2}) / \mathrm{SSQDX} 2$

ANUNEQ $=(1.0 D 0 /(\mathrm{ANl}-2 . \mathrm{ODO})) *((\mathrm{VI} /(\mathrm{VI}+\mathrm{V} 2)) * * 2)+(1.0 \mathrm{DO} /(\mathrm{AN} 2-2 . \mathrm{ODO})) *($

$1(\mathrm{~V} 2 /(\mathrm{V} 1+\mathrm{V} 2)) * * 2)$

ANUNEQ $=1$. ODO/ANUNEQ 
NUEQ $=A N U E Q+0.1 D 0$

NUNEQ $=A N U N E Q+0.1 D 0$

IF (NUEQ. LE . 30$)$ GEQ $=\mathrm{Z}(\mathrm{NUEQ})$

IF (NUEQ . GT . 30) GEQ =1.96D0*DSQRT ( ANUEQ/ (ANUEQ-2 . OD0 ) )

IF (NUNEQ . LE . 30 ) GNEQ $=Z$ ( NUNEQ)

IF (NUNEQ . GT . 30) GNEQ=1 .96D0*DSQRT ( ANUNEQ/ (ANUNEQ-2 . ODO ) )

$P P=(P+1.0 D 0) / 2.0 D 0$

$H P P=100.0 D 0 * P P$

C

C

C

C

WRITE OUT THE INPUT DATA

IT IS ASSUMED THAT THE OUTPUT UNIT IS 6 . IF THIS IS NOT THE CASE, THEN

C

IP $=6$

WRITE (IP, 998)

WRITE (IP, 170)

WRITE (IP, 999)

WRITE (IP, 180)

WRITE (IP, 999)

WRITE ( IP, 190) AN1, AN2

WRITE (IP , 200) XBARI, XBAR2

WRITE (IP, 210) SSQDX1, SSQDX2

WRITE ( IP , 220) ALP1 , ALP2

WRITE (IP , 230) BET1, BET2

WRITE ( IP , 240) RSD1 , RSD2

WRITE ( IP , 999)

WRITE (IP, 250)P

WRITE (IP, 999)

WRITE ( IP , 260) HPP , NUEQ, GEQ

C WRITE ( IP , 270 ) HPP , NUNEQ , GNEQ

C

C

C

COMPUTE THE RATIO OF THE LARGER ESTIMATED RESIDUAL VARIANCE TO THE SMALLER ESTIMATED RESIDUAL VARIANCE

RATIO $=\left(\right.$ RSD $1{ }^{*}$ RSD 1$) /($ RSD $2 *$ RSD2 $)$

$\mathrm{AM}=\mathrm{AN} 1-2.0 \mathrm{ODO}$

$\mathrm{AN}=\mathrm{AN} 2-2 . \mathrm{ODO}$

IF (RATIO.GT . 1. ODO) GOTO110

RATIO=1.ODO/RATIO

HOLD $=A M$

$\mathrm{AM}=\mathrm{AN}$

$\mathrm{AN}=\mathrm{HOLD}$

110 WRITE (IP, 999)

$\mathrm{MI}=\mathrm{AM}+0.1$

$\mathrm{NI}=\mathrm{AN}+0 . \mathrm{I}$

WRITE (IP, 280) RATIO

WRITE ( IP , 310) MI , NI

WRITE (IP, 999)

WRITE ( IP , 290) AML

WRITE (IP, 999)

WRITE (IP, 300) S

WRITE (IP, 999)

C

WRITE (IP , 999)

C

COMPUTE THE COEFFICIENTS OF THE QUADRATIC EQUATION FOR THE EQUAL VARIANCES CASE

WRITE ( IP , 340)

WRITE (IP, 999)

$\mathrm{Al}=\mathrm{DELBET}^{*} * 2$

$\mathrm{A} 2=\mathrm{S}^{*} \mathrm{~S}^{*} \mathrm{GEQ}{ }^{*} \mathrm{GEQ}$ 


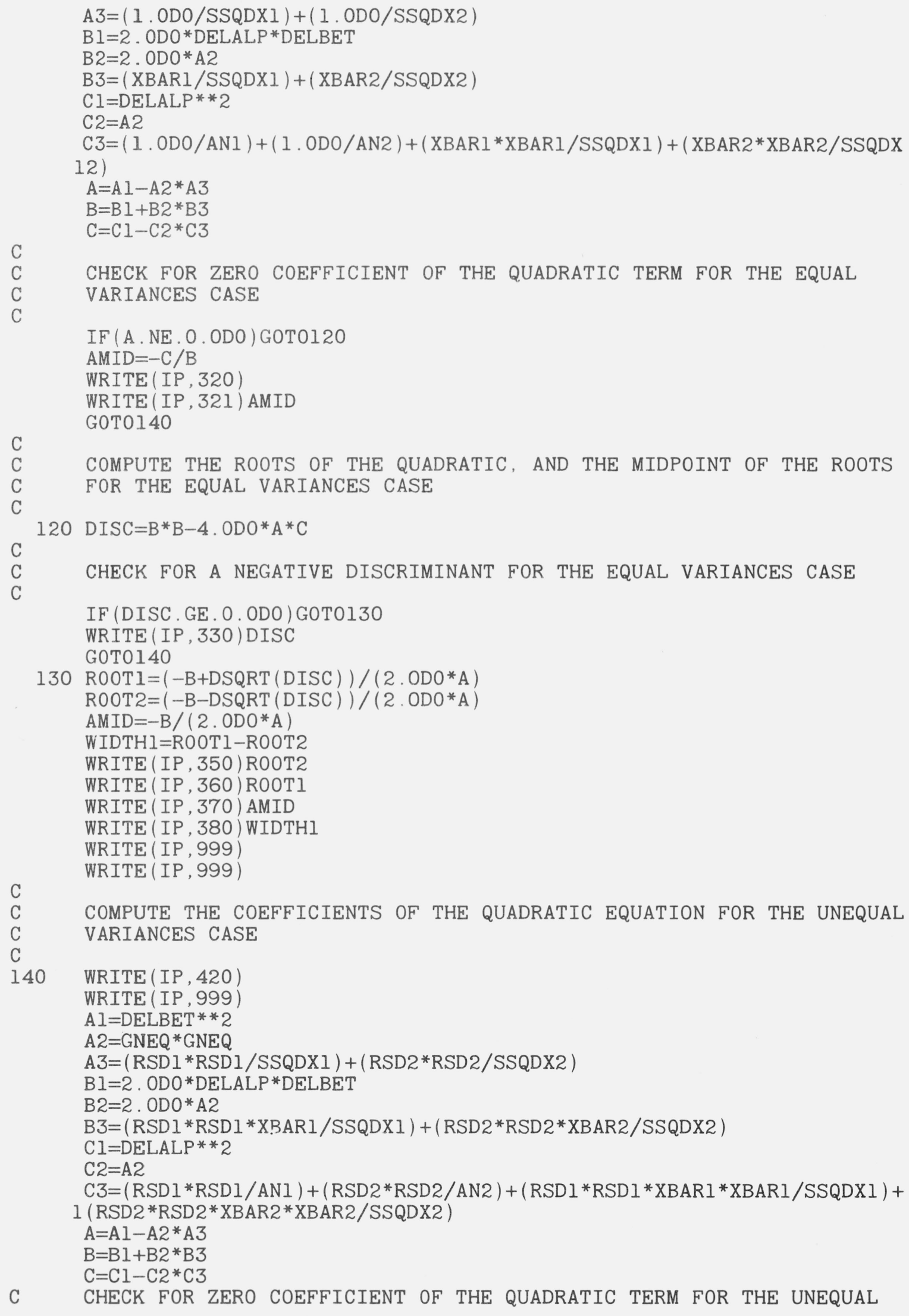


IF (A . NE . O . ODO ) GOTO150

$A M I D=-C / B$

WRITE (IP , 400)

WRITE ( IP , 321 ) AMID

RETURN

C

COMPUTE THE ROOTS OF THE QUADRATIC, AND THE MIDPOINT OF THE ROOTS FOR THE UNEQUAL VARIANCES CASE

C C

C CHECK FOR A NEGATIVE DISCRIMINANT FOR THE UNEQUAL VARIANCES CASE

IF (DISC.GE . O . ODO) GOTO160

WRITE (IP , 410) DISC RETURN

160 ROOTI $=(-\mathrm{B}+\mathrm{DSQRT}(\mathrm{DISC})) /(2.0 \mathrm{DO} * \mathrm{~A})$

$\mathrm{ROOT} 2=(-\mathrm{B}-\mathrm{DSQRT}(\mathrm{DISC})) /(2.0 \mathrm{DO} * \mathrm{~A})$

$\mathrm{AMID}=-\mathrm{B} /\left(2 . \mathrm{ODO}{ }^{*} \mathrm{~A}\right)$

WIDTH2=ROOT1-ROOT2

RATWID $=$ WIDTH2/WIDTH1

WRITE ( IP , 350) ROOT2

WRITE (IP , 360) ROOTI

WRITE ( IP , 370 ) AMID

WRITE (IP , 380) WIDTH2

WRITE (IP, 999)

WRITE (IP, 999)

WRITE ( IP , 390) RATWID

RETURN

C

170 FORMAT(IH ,58HSTATISTICAL ANALYSIS OF INTERSECTION OF 2 REGRESSION 1 LINES )

180 FORMAT ( $1 \mathrm{H}$, , IOHINPUT DATA)

190 FORMAT $(1 \mathrm{H}, 9$ HAN1 $=, \mathrm{D} 15.8,10 \mathrm{X}, 9 \mathrm{HAN} 2=, \mathrm{D} 15.8)$

200 FORMAT $(1 \mathrm{H}, 9$ HXBARI $=, \mathrm{D} 15.8,10 \mathrm{X}, 9$ HXBAR2 $=, \mathrm{D} 15.8)$

210 FORMAT $(1 \mathrm{H}, 9 \mathrm{HSSQDX} 1=, \mathrm{D} 15.8,10 \mathrm{X}, 9 \mathrm{HSSQDX} 2=, \mathrm{D} 15.8)$

220 FORMAT $(1 \mathrm{H}, 9$ HALP1 $=, \mathrm{D} 15.8,10 \mathrm{X}, 9$ HALP2 $=, \mathrm{D} 15.8)$

230 FORMAT $(1 \mathrm{H}, 9$ HBETI = ,D $15.8,10 \mathrm{X}, 9 \mathrm{HBET} 2=, \mathrm{Dl} .8)$

240 FORMAT $(1 \mathrm{H}, 9$ 9HRSD1 $=$, D 15.8,10X,9HRSD2 $=$, D 15.8$)$

250 FORMAT $(1 \mathrm{H}, 52 \mathrm{H} 2-$ SIDED CONFIDENCE INTERVALS WITH PROBABILITY WIDTH $1, \mathrm{D} 12.5,13 \mathrm{H}$ ARE PROVIDED)

260 FORMAT $(1 \mathrm{H}, 4 \mathrm{HTHE}, \mathrm{D} 12.5,42 \mathrm{H}$ PERCENT POINT OF THE T DISTRIBUTION WI $1 \mathrm{TH}, \mathrm{I} 6,50 \mathrm{H}$ DEGREES OF FREEDOM (THE EQUAL VARIANCES CASE) IS ,D12.5 1)

270 FORMAT ( $1 \mathrm{H}, 4 \mathrm{HTHE}, \mathrm{D} 12.5,42 \mathrm{H}$ PERCENT POINT OF THE T DISTRIBUTION WI $1 \mathrm{TH}$, I6,52H DEGREES OF FREEDOM (THE UNEQUAL VARIANCES CASE) IS ,DI2 $1.5)$

280 FORMAT(1H , 98HTHE RATIO OF THE LARGER ESTIMATED RESIDUAL VARIANCE ITO THE SMALLER ESTIMATED RESIDUAL VARIANCE IS ,D15.8)

290 FORMAT $(1 \mathrm{H}, 35$ HTHE MAXIMUM LIKELIHOOD ESTIMATOR $=$,D15.8)

300 FORMAT $(1 \mathrm{H}, 4 \mathrm{HS}=, \mathrm{D} 15.8)$

310 FORMAT ( $1 \mathrm{H}, 79$ HCOMPARE THE ABOVE RATIO VALUE TO THE PERCENT POINTS IOF THE F DISTRIBUTION WITH , I6,5H AND, I6, 19H DEGREES OF FREEDOM)

320 FORMAT ( $1 \mathrm{H}, 86 \mathrm{H}^{* * * * * E R R O R--T H E ~ C O E F F I C I E N T ~ O F ~ T H E ~ Q U A D R A T I C ~ T E R M ~ I S ~}$ 1 ZERO FOR THE EQUAL VARIANCES CASE)

321 FORMAT $(1 \mathrm{H}, 57 \mathrm{H}$ THE CONFIDENCE INTERVAL HAS ZERO WIDTH A IBOUT , D15.8)

330 FORMAT ( $1 \mathrm{H}, 97 \mathrm{H}^{* * * * * E R R O R--N E G A T I V E ~ D I S C R I M I N A N T ~ I N ~ T H E ~ E Q U A L ~ V A R I A ~}$ INCES CASE. THE VALUE OF THE DISCRIMINANT IS ,D15.8) 
340 FORMAT ( $1 \mathrm{H}, 20 \mathrm{HEQUAL}$ VARIANCES CASE)

350 FORMAT ( IH , 37HLOWER LIMIT OF CONFIDENCE INTERVAL $=$,D 15.8)

360 FORMAT $(1 \mathrm{H}, 37$ HUPPER LIMIT OF CONFIDENCE INTERVAL $=$,D15.8)

370 FORMAT $(1 \mathrm{H}, 3$ 3HMIDPOINT OF CONFIDENCE INTERVAL $=$,D 15.8$)$

380 FORMAT $(1 \mathrm{H}, 37 \mathrm{HWIDTH}$ OF CONFIDENCE INTERVAL = ,D15.8)

390 FORMAT $(1 \mathrm{H}$, 46HTHE RATIO OF THE CONFIDENCE INTERVAL WIDTHS = , DI5.8 1)

400 FORMAT $\left(1 \mathrm{H}, 88 \mathrm{H}^{* * * * *}\right.$ ERROR--THE COEFFICIENT OF THE QUADRATIC TERM IS

1 ZERO FOR THE UNEQUAL VARIANCES CASE)

410 FORMAT $\left(1 \mathrm{H}, 99 \mathrm{H}^{* * * * *}\right.$ ERROR--NEGATIVE DISCRIMINANT IN THE UNEQUAL VAR

IIANCES CASE. THE VALUE OF THE DISCRIMINANT IS ,DI5.8)

420 FORMAT ( $1 \mathrm{H}, 22 \mathrm{HUNEQUAL}$ VARIANCES CASE)

998 FORMAT ( $1 \mathrm{HI})$

999 FORMAT ( 1 HO)

END

STATISTICAL ANALYSIS OF INTERSECTION OF 2 REGRESSION LINES

INPUT DATA

$\begin{array}{lll}\text { ANl } & = & .14000000+002 \\ \text { XBARI } & =.67500000+002 \\ \text { SSQDXI } & =.56875000+004 \\ \text { ALP1 } & =.82368597+000 \\ \text { BETI } & =.62355168-003 \\ \text { RSDI } & =.11459900-003\end{array}$

$\begin{array}{llr}\text { AN2 } & = & .11000000+002 \\ \text { XBAR2 } & = & -.50000000+001 \\ \text { SSQDX2 } & = & .27500000+004 \\ \text { ALP2 } & =.83584345+000 \\ \text { BET2 } & =.23469094-003 \\ \text { RSD2 } & =.49539027-004\end{array}$

2-SIDED CONFIDENCE INTERVALS WITH PROBABILITY WIDTH .95000+000 ARE PROVIDED

THE .97500+002 PERCENT POINT OF THE T DISTRIBUTION WITH 21 DEGREES OF FREEDOM (THE EQUAL VARIANCES CASE) IS .20796+001

THE .97500+002 PERCENT POINT OF THE T DISTRIBUTION WITH 17 DEGREES OF FREEDOM (THE UNEQUAL VARIANCES CASE) IS .21098+001

THE RATIO OF THE LARGER ESTIMATED RESIDUAL VARIANCE TO THE SMALLER ESTIMATED RESIDUAL VARIANCE IS .5351393+001

COMPARE THE ABOVE RATIO VALUE TO THE PERCENT POINTS OF THE F DISTRIBUTION WITH .12000+002 AND .90000+001 DEGREES OF FREEDOM

THE MAXIMUM LIKELIHOOD ESTIMATOR $=.31264354+002$

$S=.92500246-004$ 


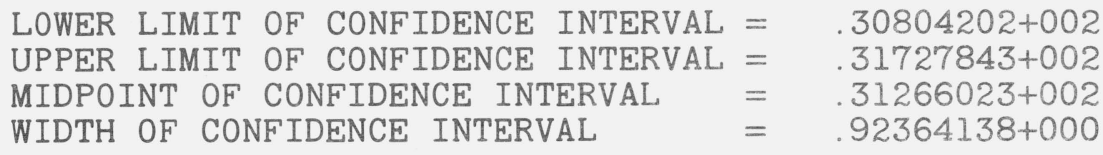

UNEQUAL VARIANCES CASE

LOWER LIMIT OF CONFIDENCE INTERVAL $=.30865357+002$

UPPER LIMIT OF CONFIDENCE INTERVAL $=.31660331+002$

MIDPOINT OF CONFIDENCE INTERVAL $=.31262844+002$

WIDTH OF CONFIDENCE INTERVAL $=.79497346+000$

THE RATIO OF THE CONFIDENCE INTERVAL WIDTHS $=.86069493+000$

\section{References}

[1] Fisher, R. A., Statistical Methods for Research Workers, 11th edition, 144-146 (Oliver and Boyd, 1950).

[2] Kastenbaum, M. A., A confidence interval on the abscissa of the point of intersection of two fitted linear regressions, Biometrics 15, 323-324. (1959).

[3] Hinkley, D. V., Inference about the intersection in two-phase regression, Biometrika 56, 495-504. (1969).

[4] Robison, D. E., Estimate for the points of intersection of two polynomial regressions, J. Am. Statistical Asn. 59, 214-224 (1964).

[5] Hudson, D. J., Fitting segmented curves whose join points have to be estimated, J. Amer. Stat. Assoc. 61, 1097-1129 (1966).

[6] Bennett, Carl A. and Franklin, Norman L., Statistical Analysis in Chemistry and the Chemistry Industry (John Wiley \& Sons, New York, 1954). pp 176-180.

[7] Aspin, A. A., An examination and further development of a formula arising in the problem of comparing two mean values, Biometrika 35, 88 (1948).

[8] Aspin, A. A., Tables for use in comparisons whose accuracy involves two variances, separately estimated, Biometrika 36, 290 (1949).

[9] Welch, B. L., The generalisation of "Student's" problem when several different population variances are involved, Biometrika 34, 28 (1947).

[10] McKinney, J. E., and Belcher, H. V., to be published.

(Paper 76B3\&4-370) 